\title{
LA ANTROPOLOGÍA APLICADA A LOS NEGOCIOS INTERNACIONALES: ENCUENTROS Y DESENCUENTROS*
}

\author{
Recibido: 27 de enero de 2014 Aprobado: 20 de agosto 2015
}

Juan Carlos Herrera Ruiz**

\section{RESUMEN}

Este artículo plantea una reflexión en torno a la aplicación de las teorías y métodos de la antropología en algunos aspectos prácticos de la administración que interesan a los negocios internacionales, tales como como la cultura organizacional, la investigación de mercados y la dimensión intercultural que caracteriza a esta actividad en el ámbito global. Se exploran algunas fuentes bibliográficas y aportes de investigadores representativos que ilustran sobre el desarrollo profesional y académico y los debates que se generan en el interior de esta sub-especialidad de la antropología en la Contemporaneidad. Se concluye que instrumentalizar el conocimiento científico sobre el comportamiento cultural al servicio del poder corporativo plantea problemas de orden ético.

\section{PALABRAS CLAVE}

Antropología económica, antropología de los negocios.

\section{CLASIFICACIÓN JEL}

Z13; M19

\section{CONTENIDO}

Introducción; 1. ¿Por qué son útiles los antropólogos para las organizaciones y en general para la economía de libre mercado?; 2. Ejemplos de aplicación de la Antropología a los Negocios Internacionales; 3. Crítica a la razón de los negocios; Bibliografía.

* El artículo es producto del proyecto de investigación titulado "Modelo antropológico para la motivación de usuarios en procesos de innovación abierta", desarrollado de manera autofinanciada entre los años 2013 y 2014 por un equipo interdisciplinario compuesto por miembros del Centro de Investigaciones en Ingeniería -CEIB-y el Centro de Investigaciones Económicas, Administrativas y Contables -CIECA- de la Universidad de Medellín. El artículo es una reflexión en torno al marco teórico del referido proyecto, en particular en lo que atañe al componente socio-antropológico.

** Antropólogo y licenciado en Educación, Universidad de Antioquia, Medellín, Colombia. Magíster en Literatura, Universidad de Antioquia, Medellín, Colombia. Estudiante del Doctorado en Literatura, Universidad de Antioquia, Medellín, Colombia. Profesor auxiliar de la Facultad de Ciencias Económicas y Administrativas de la Universidad de Medellín, Medellín, Colombia. Miembro del grupo de investigación en negocios y relaciones internacionales del programa de Negocios Internacionales. Carrera 87 N. 30-65. Bloque 7-106. Medellín, Colombia. Correo electrónico: jcherrera@udem.edu.co. 


\section{APPLIED ANTHROPOLOGY FOR INTERNATIONAL BUSINESS: CONVERGENCE AND DIVERGENCE}

\section{ABSTRACT}

This article reflects upon the application of anthropology theories and methods over certain practical administration aspects that are of interest to international business, such as organizational culture, market research and the intercultural dimension that characterizes this activity in a global environment. In order to illustrate this, some bibliographical sources and contributions made by representative researchers on professional and academic development are explored as well as the internal debates that are happening within this sub-spatiality of Anthropology now a days. It is concluded that when scientific knowledge is applied over the cultural behavior to the service of corporate power, it those bring with it ethical issues.

\section{KEY WORDS}

Economic Anthropology, Business Anthropology.

\section{JEL CLASSIFICATION}

Z13; M19

\section{CONTENT}

Introduction; 1. Why are anthropologists useful for organizations and in general for the free market economy? 2. Examples of Anthropology application in International Business; Criticism to the reason of businesses; Bibliography.

\section{A ANTROPOLOGIA APLICADA AOS NEGÓCIOS INTERNACIONAIS: ENCONTROS EDESENCONTROS}

\section{RESUMO}

Este artigo planteia uma reflexão em torno à aplicação das teorias e métodos da antropologia em alguns aspectos práticos da administração que interessam aos negócios internacionais, tais como a cultura organizacional, a investigação de mercados e a dimensão intercultural que caracteriza a esta atividade no âmbito global. Se exploram algumas fontes bibliográficas e aportes de investigadores representativos que ilustram sobre o desenvolvimento profissional e académico e os debates que se geram ao interior desta subespecialidade da Antropologia na contemporaneidade. Se conclui que instrumentalizar o conhecimento científico sobre o comportamento cultural ao serviço do poder corporativo planteia problemas de ordem ético.

\section{PALAVRAS CHAVE}

Antropologia económica, Antropologia dos negócios.

\section{CLASSIFICAÇÃO JEL}

\section{Z13; M19}

\section{CONTEÚDO}

Introdução; 1.Por que são úteis os antropólogos para as organizações e em geral para a economia de livre mercado?; 2. Exemplos de aplicação da Antropologia aos Negócios Internacionais; 3. Crítica à razão dos negócios; Bibliografia. 


\section{INTRODUCCIÓN}

La antropología de los negocios, como se nombra en manuales y revistas especializadas, hace parte de un dominio conceptual más extenso conocido como antropología aplicada, que se concibe como la aplicación de los principios teóricos y metodológicos de la antropología al estudio de un amplio rango de actividades sociales. Estas actividades, señalan Kedia y Van Willigen (2005), abordan un número cada vez mayor de fenómenos asociados a la educación, el derecho, el arte, la medicina, la política y la diplomacia, el desarrollo económico y tecnológico, la administración de empresas e industrias, la agricultura, el medio ambiente, entre muchos otros campos o dominios en los que la participación de especialistas en antropología facilita una comprensión más profunda de los estilos de vida humana y de los modos en los que, en su complejidad, las diversas comunidades organizan la propia experiencia de la realidad.

Por tratarse de aspectos esenciales de la vida social, el intercambio de bienes y servicios y las relaciones económicas en general están en el foco de atención de los antropólogos y de la teoría antropológica. En el ámbito de los negocios internacionales, en tanto actividad culturalmente determinada, la antropología ha ganado gran pertinencia como instrumento para la resolución de problemas de orden gerencial y de recursos humanos, la toma de decisiones estratégicas, el manejo de conflictos en el interior de las organizaciones, la motivación, las investigaciones de mercado y el desarrollo de nuevos productos y servicios, el estudio y la caracterización de perfiles de consumidores y dinámicas de consumo, ello a través de la puesta en práctica de métodos clásicos como el de la observación-participación, las entrevistas estructuradas, el análisis lingüístico, entre muchas otras herramientas etnográficas de recolección de información cualitativa in situ1 ${ }^{1}$, que han demostrado ser de enorme utilidad para la comprensión del mundo de las corporaciones y de la así llamada cultura organizacional, según arguyen autores como Aguilera (1996); Ferraro (2005); Francesco y Gold (2005); Baba (2006); Jordan (2010); Tian y College (2010) y Van Marrewijk (2010).

En el campo de la formación académica de profesionales en negocios internacionales, así como en las tendencias de la investigación, la Antropología ocupa un espacio cada vez más importante en los planes curriculares de los programas de pre y posgrado, en los contenidos de las asignaturas relacionadas con el comercio internacional, en la interculturalidad y, desde luego, en el entrenamiento impartido

1 Locución adverbial para indicar que el trabajo se realiza en el lugar objeto de interés o de estudio, en este caso, las instalaciones físicas en las que determinada empresa u organización desarrolla sus labores productivas y administrativas o, bien, en los espacios en los que consumidores, productos y servicios entran en contacto. 
a profesionales del marketing en los diferentes niveles de sub-especialización, como lo sugieren Sherry (1988); Chapman (2001) y Tian y Walle, (2009). En esta misma dirección, la relación instrumental entre la antropología y los negocios internacionales atrae a un conjunto de especialistas cada vez más heterogéneo, entre los que se cuentan los profesores de negocios con formación en Antropología socio-cultural, los antropólogos que han hecho de los negocios un campo independiente de investigación, los consultores de negocios y otros entes facultativos que, provistos de información sobre el comportamiento cultural, asesoran a empresas e industrias en el desarrollo de nuevos productos y servicios.

Esta multiplicidad de expresiones de la aplicabilidad de la teoría y los métodos antropológicos a la práctica de los negocios internacionales ha llevado a que grandes organizaciones productivas y escuelas de negocios recluten, en un número cada vez mayor, antropólogos y otros profesionales provenientes de las ciencias sociales. En consecuencia, el grado de pertinencia ganado en los ámbitos académico y empresarial, siempre a la sombra del discurso de la globalización económica y gracias a los resultados prácticos que evidencian la eficacia de sus métodos, hace que la antropología de los negocios goce hoy en día de reconocimiento como especialidad consolidada, dotada de un marco teórico-metodológico propio, campos y redes de investigación que impactan sectores sensibles de la industria y la cultura organizacional, ello a través del flujo continuo de información en publicaciones científicas², o bien como lo plantea Walle (2003), por medio de la puesta en práctica de premisas teóricas en actividades de consultoría para empresas y negocios de diversa tipología.

Sin embargo, esta multiplicidad de aplicaciones ha llevado también a que la antropología de los negocios se ubique hoy en una frontera imprecisa entre dos tendencias. La primera de ellas derivada del interés científico por comprender la actividad de los negocios internacionales, entendida como institución de intercambio y en términos de la universalidad cultural, relacionada con el uso y distribución social de los recursos. La otra tendencia, más proclive a los valores y principios de las corporaciones, se deriva de la razón lucrativa que en Occidente subyace y da sentido a la práctica de los negocios, en una economía de mercado globalizada cuya meta es la maximización de los ganancias y la reducción de los costos, aun en detrimento de aquellas culturas y comunidades en las cuales las decisiones económicas no son motivadas por el lucro, o bien donde lo que se entiende por lucro adquiere otros matices no siempre compatibles con la idiosincrasia y el sentido práctico occidentales.

2 El IJBA (International Journal of Business Anthropology) es una fuente de primer orden para acceder a la actividad intelectual de los expertos en la materia en el ámbito internacional y a los más recientes debates que ocupan la atención de teóricos e investigadores. 
Este articulo reflexiona sobre la percepción que se tiene de la antropología desde el ámbito operativo de los negocios internacionales y los alcances de esta sub-especialidad, a partir de una re-lectura de algunos postulados acuñados por investigadores y especialistas que durante las últimas décadas han documentado y defendido la aplicabilidad de la teoría y métodos antropológicos en los ámbitos empresariales y en aras de la producción de lucro; ello en oposición a planteamientos críticos que, desde la otra orilla, advierten, en esta instrumentalización de la disciplina, una subordinación moral e intelectual a los valores del poder corporativo, a la preservación de las desigualdades económicas entre países y comunidades y en algunos casos a la restauración de prácticas colonialistas.

Para tal propósito, se revisaron algunos artículos del International Journal of Business Anthropology que ilustran sobre las tendencias en investigación durante la última década y en donde se plantean problemas epistemológicos clave para entender la dimensión y el alcance de este campo de estudios; en la misma dirección, se exploraron algunos de los estudios considerados por quien escribe clásicos o fundacionales, en los que se formulan pautas teórico-prácticas respecto a las instituciones de intercambio económico y, por extensión, al actual rol de los antropólogos en el ámbito organizacional; se retoman, asimismo, algunos aportes y las preguntas formuladas por autores contemporáneos, que enfocan su atención en el debate ético que supone esta instrumentalización de la antropología.

El artículo se divide en 3 secciones: la primera tiene que ver con una ilustración y contextualización del tema a tratar, se aborda el tema de la antropología de los negocios desde diferentes perspectivas y se hace un recuento de su evolución y aplicación en el campo económico. En la siguiente sección se analiza la utilidad y pertinencia de los antropólogos al interior de las organizaciones y en el panorama actual de una economía globalizada donde impera el libre comercio. Finalmente, se muestran algunos ejemplos de la antropología aplicada a los negocios y se hace un aparte con las reflexiones y conclusiones finales.

\section{1. ¿POR QUÉ SON ÚTILES LOS ANTROPÓLOGOS PARA LAS ORGANIZACIONES Y EN GENERAL PARA LA ECONOMÍA DE LIBRE MERCADO?}

La antropología ha otorgado siempre especial atención a las instituciones de intercambio y en general a las relaciones económicas, como parte sustancial de la vida material y sociocultural de las comunidades humanas. Entre los trabajos paradigmáticos que marcaron desde principios del siglo XX la tradición de los estudios antropológicos sobre la vida económica de los seres humanos, sobresale el célebre Essai sur le don de Marcel Mauss (2009), obra que salió a la luz en 1924 y se 
convirtió en una especie de piedra angular para muchas elaboraciones teóricas en torno a las cadenas de intercambio y circulación de bienes que, según Mauss (2009), son el origen mismo de la vida social, gracias no solo al valor que culturalmente se atribuye a los objetos o bienes intercambiados, sino también a las relaciones y vínculos sociales que se forman entre grupos o individuos por medio de las actividades de intercambio.

Otro de los trabajos clásicos que pretendieron formular una teoría científica que explicara los fenómenos asociados al intercambio económico, en términos de la funcionalidad dentro de la cultura, fue el estudio que durante la Primera Guerra Mundial realizó Malinowski (2001) sobre el Kula, un complejo sistema de comercio ritual practicado por los indígenas de las Islas Trobriand, uno de los miles de archipiélagos de los que se compone la Micronesia, en el Pacífico sur. En este sistema que documentó por primera vez Malinowski (2001), los isleños participan de un circuito de intercambios en el que circulan solo dos tipos de objetos: brazaletes y collares fabricados con conchas marinas. La participación en el Kula es la práctica social más importante para los habitantes de esa comunidad, dado que gracias a ello mantienen vigentes y crean nuevas relaciones sociales con grupos de islas vecinas. Así, el valor atribuido a los objetos intercambiados es subsidiario del valor de los compromisos económicos, de parentesco y en general de reconocimiento mutuo que se establecen con otras comunidades a través del intercambio.

Sin embargo, emerge la duda de si estas aproximaciones teóricas, formuladas con base en la observación de sociedades pre-industriales donde no existía el valor de cambio monetario, son pertinentes para el estudio de los fenómenos de intercambio económico, tal y como se presentan en sociedades contemporáneas en Occidente, gobernadas por las leyes y la lógica del mercado, que ahora se define como global. De otra parte y sin soslayar que los enfoques de Mauss (2009) y Malinowski (2001) son apenas dos de los ejemplos más representativos de una larga lista de propuestas teóricas de mayor o menor grado de innovación, aparecidas en el siglo XX y lo que va del XXI, cabe preguntarse si la función social de la disciplina antropológica, sus métodos y su teoría deberían limitarse a la descripción e interpretación de las instituciones de intercambio económico, de las dinámicas sociales y las formas que adquieren en la Contemporaneidad o si también constituye parte de la evolución como ciencia social el contribuir a que esas instituciones lleguen a ser exitosas, desde luego en términos de lo que en el ámbito de los negocios internacionales se entiende hoy por exitoso.

Para dar respuesta a este interrogante es necesario acudir a una de las categorías esenciales de la antropología como discurso teórico: la cultura. A través de los siglos 
XIX y XX se ha generado multiplicidad de definiciones, y desde corrientes como el evolucionismo, el particularismo histórico, el funcionalismo o el estructuralismo, se plantearon modelos para explicar qué es, de dónde proviene y cómo se expresa la cultura en términos históricos, biológicos, ideológicos, semióticos y, desde luego, económicos, de suerte que toda aproximación académica al campo de la cultura o de lo cultural parte necesariamente de una perspectiva antropológica, y se atribuye a esta disciplina el papel de emisor natural del conocimiento científico sobre la cultura. De ahí también que los antropólogos sean un gremio apetecible en el ámbito de la administración y los negocios, cuyos teóricos y académicos se encuentran persuadidos del cultural awareness que subyace a todas las actividades económicas y de los cambios que en la Contemporaneidad experimentan los ambientes de negocios, entendidos ahora como ambientes globales.

Esta valoración del rol potencial de los antropólogos en las empresas y organizaciones reside también en que aquellos estarían presuntamente entrenados, en mayor o menor medida y de acuerdo con la especialidad, para percibir las ecuaciones simbólicas a través de las cuales se manifiestan los deseos y necesidades humanas, las motivaciones y expectativas, incluso los temores, a fin de hacerlos inteligibles para gerentes y administradores de negocios y ponerlos al servicio de estrategias de mercadeo acertadas. Asimismo, los antropólogos estarían en capacidad de distinguir las diferencias culturales y valores en el interior de las organizaciones, y sobre la base de esa distinción ayudar a posibilitar relaciones económicamente eficientes entre empresarios, empleados y clientes.

Con respecto a lo anterior, cabría también preguntarse si la instrumentalización de la antropología en favor de las prácticas gerenciales y de la búsqueda del lucro económico no termina por convertir esta disciplina en un espacio más de la economía de mercado, y a los antropólogos, en parte de la composición orgánica del capital de las corporaciones. De otra parte, emerge el debate epistemológico en cuanto a la aplicabilidad de las conjeturas teóricas y métodos cualitativos de la antropología al campo de los negocios, cuya dinámica se expresa, en esencia, a partir de métodos y lenguajes cuantitativos. Esta discusión ha sido abordada por multiplicidad de investigadores y las posiciones al respecto fluctúan entre quienes consideran pertinente y legítimo poner la teoría y los métodos de la antropología al servicio de organizaciones productivas que buscan el lucro, y quienes consideran que ello constituye una desviación artificiosa de las teorías de la cultura.

El primer argumento que esgrimen los defensores de la participación de antropólogos en organizaciones con fines lucrativos es que ello obedece a una tendencia contemporánea en la que el objeto de la antropología se desplaza del típico exotismo 
de las comunidades aborígenes pre-industriales, hacia los contextos propios del observador, es decir, sociedades complejas de carácter nacional, imbuidas en un sistema internacional, regido por un modelo emergente de organización política y económica -la globalización-, del cual, según Jordan (2010), la antropología no puede ni debe abstraerse. Asimismo, investigadores como Tian y College (2010) y Walle (2013) sostienen que en muchas partes del tercer mundo, la oportuna intervención de antropólogos de negocios ha contribuido al mejoramiento de la calidad de vida de comunidades marginales, a través del apoyo a pequeñas y medianas iniciativas de emprendimiento, el acceso a nuevos productos y tecnologías, la puesta en marcha de proyectos de explotación sostenible de recursos naturales, el saneamiento ambiental, el empoderamiento de minorías étnicas junto la protección de patentes y derechos de propiedad intelectual, entre otras innovaciones que, según ellos, hacen compatibles la esencia lucrativa de la economía de libre mercado con las necesidades de desarrollo.

Pero no solo las escuelas y los especialistas del management han comprendido el potencial de la antropología en el mundo de los negocios y las corporaciones; en modo recíproco, en un número cada vez más importante de universidades en Estados Unidos y en Europa occidental se viene cultivando una tendencia académicopráctica, que propende por formar antropólogos con habilidades y destrezas en el campo de los negocios, el mercadeo y la cultura organizacional. Esto en razón de que la globalización ha influenciado no solo los negocios sino también las disciplinas sociales, disciplinas que, hoy más que nunca, precisan de innovación y de flexibilidad ideológica, de suerte también que se pueda diversificar el rango de posibilidades laborales de los profesionales. Todo lo anterior sustentado en la premisa de que la antropología puede y debe aplicar las teorías y métodos a la práctica social de los negocios y contribuir con ello a que todo tipo de empresas y organizaciones, grandes o pequeñas, locales o internacionales, sean más eficientes y rentables, como lo consideran Roca (2001), Tian y College (2010), y Van Marrewijk (2010).

Son diversas las aproximaciones que pretenden dar cuenta de la trayectoria, el desarrollo y la configuración de un objeto de estudio para la antropología de los negocios, bien como instrumento teórico-metodológico puesto al servicio de la ejecución de negocios, o bien como materia de investigación académica. La pertinencia de la antropología aplicada ya había sido evidenciada durante y después de la Segunda Guerra Mundial, en lo que tiene que ver con la toma de decisiones estratégicas. Citando a algunos autores como Eddy y Partridge (1978) sobre el ascenso de la antropología aplicada en Norteamérica ${ }^{3}$, Walle (2013, p.115) recuerda figuras insignes de la disciplina como Ruth Benedict, Margaret Mead, Clyde Kluckhohn,

3 Applied Anthropology in America. 
entre otras, que durante y después de la Segunda Guerra Mundial, colaboraron con el Departamento de Estado y el ejército de los Estados Unidos en el desarrollo de estrategias de aproximación a las peculiaridades culturales y en general a los símbolos y tradiciones consuetudinarias de los japoneses, entonces el enemigo. En este orden de ideas, Walle (2013) registra también la existencia de una vasta documentación que evidencia la forma cómo durante la primera mitad del siglo XX reconocidas compañías estadounidenses, del orden local y del internacional, tomaron en cuenta las recomendaciones de antropólogos socio-culturales en la formulación de la visión y la misión institucionales, de las pautas de liderazgo y en la definición de lo que aquellas compañías consideraban debían ser los valores como organizaciones productivas.

A partir de los años setenta, como lo sugieren Aguilera (1996) y Baba (2006) se hizo frecuente que directivos de grandes compañías solicitaran la asesoría de académicos provenientes del campo de las ciencias sociales, psicólogos, sociólogos, pero en especial antropólogos, en estrategias de re-ingeniería empresarial, basándose en procesos de introspección y revisión de los propios paradigmas administrativos y en correspondencia con las transformaciones que ya desde entonces venía experimentando la forma de hacer negocios a escala planetaria, en ambientes multiculturales y bajo el influjo temprano de las tecnologías de la información y las comunicaciones.

\section{EJEMPLOS DE APLICACIÓN DE LA ANTROPOLOGÍA A LOS NEGOCIOS INTERNACIONALES}

Jordan (2010) propone un modelo que discrimina la antropología de los negocios contemporánea en tres grandes campos. El primero busca estudiar las formas en que se configuran las organizaciones en su complejidad cultural, estructura administrativa y procesos productivos. El segundo, y quizá el más popular tanto entre empresarios como entre los antropólogos mismos, se enfoca en las dinámicas del mercado y el comportamiento de los consumidores. El tercero y último de estos campos es una derivación del segundo y se relaciona con el diseño de nuevos productos y servicios.

Tian y College (2010) argumentan que tanto los teóricos de la administración de negocios como los dirigentes empresariales se encuentran cada vez más persuadidos de que técnicas elementales del trabajo etnográfico, como la observación participación o la aplicación de encuestas, constituyen un instrumento eficaz para la aproximación, en el interior de las organizaciones, a la cotidianidad productiva. En esa misma dirección, Jordan (2010) estima que la identificación y la documentación de las diferencias culturales dentro de las compañías, derivadas de las diferencias sociales y del cambio cultural que cíclicamente experimentan todas las sociedades, 
contribuyen a hacer más acertadas y menos riesgosas las inversiones en nuevos negocios y las alianzas estratégicas entre empresas de diversa tipología y origen.

Entre las tendencias contemporáneas de la investigación en gestión del conocimiento y cultura organizacional, sobresalen la vigilancia tecnológica y la inteligencia competitiva (VTIC), campos en los que los antropólogos de negocios también han hecho contribuciones valiosas en el terreno de la innovación, las habilidades gerenciales y la toma de decisiones estratégicas, tal y como lo documentan Tian, Wang y Dai (2013). En ese sentido, recabar y hacer fluir información sobre el modo en que se auto-perciben los diferentes grupos que conforman una determinada organización productiva y cómo perciben el entorno se logra gracias a la infiltración de antropólogos en el interior y en todos los niveles jerárquicos de la misma: desde la línea de producción hasta el despacho de alguno de los directores ejecutivos. Tian y College (2010) sostienen, además, que el campo en que con mayor frecuencia se aplica la perspectiva del análisis cultural tiene que ver con la resolución de conflictos en el interior de las organizaciones. Se ha reconocido la eficacia de la intervención de antropólogos cuando se trata de persuadir a aquellos miembros y empleados de empresas que oponen resistencia a los cambios: adaptación a nuevas tecnologías y esquemas productivos, directrices administrativas que modifican funciones, jerarquías o sistemas de derechos y deberes previamente establecidos, entre otra larga lista de conflictos, que pueden ser prevenidos o resueltos a través de estudios que ponderen diferencias de origen étnico-geográfico, ideológico, socioeconómico o de acceso a recursos, niveles de educación y especialización entre los miembros de una organización.

Otro rasgo de incidencia cultural que suele ser tenido en cuenta en el diseño de políticas y lenguajes gerenciales amigables, pero en especial para evitar situaciones de conflicto entre directivas y empleados, tiene que ver con estudios de cómo se construyen las relaciones laborales dentro de una empresa, particularmente con respecto a las diferencias de género, rangos de edad y todo el conjunto de intereses y percepciones de la vida, derivadas de esa variabilidad. La lectura oportuna de dichas particularidades y en general del modo en que trabajan las personas, de las dificultades que enfrentan al trabajar, de lo que manifiestan de manera verbal mientras trabajan permite, en opinión de Jordan (2010), proveer claves para una adecuada división del trabajo, asignación de roles, salarios y diseño de esquemas de premios y reconocimientos con base en las presuntas expectativas propias de los grupos o segmentos identificados. Sin embargo, esta ponderación de las diferencias culturales y el mismo enfoque culturalista en el estudio de las organizaciones no siempre logra poner a prueba los balances y las relaciones de poder dentro de estas. A este respecto Van Marrewijk (2010) cita experiencias de campo en compañías de 
los Países Bajos, en los que antropólogos tomaron parte a favor de los intereses de los empleados en situaciones de conflicto laboral o bien manifestaron solidaridad por las demandas de aquellos como colectivo, ello en razón de que, por lo general, los ejercicios etnográficos se construyen desde una perspectiva emic o del sujeto observado (en este caso la de los empleados u obreros de base de una compañía), lo que llevó a una inevitable colisión con la perspectiva del dirigente empresarial que acude al antropólogo justamente para ayudar a resolver el conflicto. Para Van Marrewijk (2010, p.36) todo depende de la cuestión: "¿para quién trabaja el antropólogo o quién paga los honorarios?".

Por ello no son solo los desencuentros sino también los puntos en común lo que, según el enfoque de la antropología de los negocios, debe tenerse en cuenta en el estudio de la cultura organizacional y las actividades de negocios. En este sentido, arguye Aguilera (1996), una contribución crucial de los antropólogos al conocimiento de la propia cultura organizacional consiste en ayudar a los dirigentes a encontrar respuestas para las siguientes preguntas: ¿Quiénes son los líderes y quiénes los subalternos en una compañía o negocio? ¿Cuántos grupos de personas están involucrados en ese negocio? ¿Cómo se relacionan y comunican entre sí los miembros de los diferentes grupos? ¿Cuáles son las causas que generan conflicto entre los grupos e individuos de una compañía o negocio y cómo se resuelven dichos conflictos? ¿Cuáles valores, creencias y actitudes tienen en común los miembros de esa compañía o negocio? ¿Cuál es la percepción que se tiene de la jerarquía política dentro una organización productiva, de acuerdo con la forma en que se ejercen el poder y la autoridad?

Como se señaló antes, la faceta que quizá más brillo aporta a esta relación entre la antropología y los negocios es aquella que se ocupa del estudio del comportamiento de los consumidores y del diseño de estrategias de mercadeo. Dado que la economía de mercado se estructura a partir de hábitos cíclicos y sistemáticos de consumo de toda suerte de productos o servicios, resulta crucial para el éxito de la misma comprender las motivaciones que orientan dichos hábitos. En este sentido, antropólogos y psicólogos sociales colaboran estrechamente con los gurús del marketing en la elaboración de manuales académicos sobre consumer behavior, y desde luego en el perfeccionamiento de los métodos a través de los cuales las compañías o negocios ofrecen un determinado bien o servicio, dónde, cuándo y a quiénes, bajo qué premisas o promesas, a qué precios etc., pero en especial los antropólogos trabajan en identificar las razones profundas que conducen a que un individuo o colectividad elija comprar determinado producto o servicio.

Tal y como ocurre en el estudio de la cultura organizacional y debido a que no todos los consumidores se comportan de la misma manera, Tian, Lillis y van 
Marrewijk (2010) sostienen que el análisis antropológico de los contextos en que se presenta el consumo tiene en cuenta no solo aquellas variables sociodemográficas generales de carácter transcultural, a saber, edad, sexo, nivel de ingreso, formación académica, sino también otras más específicas relacionadas con la parentela, la filiación étnica, la religión o la ideología política, solo por mencionar algunos ejemplos, ya que ello permite una delimitación aún más minuciosa de los segmentos del mercado y una detección aún más eficaz de los rasgos en uno u otro grupo poblacional que los hagan compradores potenciales de determinados productos 0 servicios. Ello parte del análisis de los patrones semióticos del comportamiento, asociables al consumo que también documentan Sherry (1995) y Jordan (2010), los cuales evidencian una estrategia adaptativa que permite al individuo formalizar ante sí y ante los demás un estilo de vida, provisto de valores y matices reconocibles a través de lo que consume y de cómo lo consume.

Malinowsky (1981), uno de los antropólogos más importantes del siglo XX, ya había postulado en la teoría funcionalista de la cultura que todas las acciones humanas tienen una base psico-biológica, y así mismo sostiene que cada manifestación de la cultura, bien sea en la forma de costumbres o de objetos materiales cumple una función vital: la de satisfacer las necesidades de orden psicológico y físicoorgánico que emergen en la lucha por la supervivencia. La satisfacción cabal de las necesidades llevaría a la autorrealización del individuo y es precisamente allí donde reside la motivación a participar de las instituciones sociales, entre las cuales las del intercambio económico y la circulación de bienes ostentan un carácter preponderante. En la misma línea de argumentación pero desde una perspectiva sociológica, Bourdieu (2008) plantea la existencia de un capital simbólico, como fuerza que motiva la interacción de individuos en actividades sociales -entre ellas el consumo- en las cuales la retribución o recompensa se traduce en bienes no necesariamente materiales, sino más bien en reconocimiento y competencia dentro del mismo contexto cultural y el sistema de valores. Este análisis funcional que plantean Malinowski (1984) y Bourdieu (2008) encuentra resonancia en las elaboraciones discursivas de los antropólogos de negocios en la Contemporaneidad, quienes recogen la premisa de que la existencia de ciertos hábitos o bienes en el ámbito de la cultura responde a una necesidad, en este caso simbólica, de asignar un valor distintivo a los individuos, en términos del estatus o roles que representan.

Ahora bien, en lo que atañe al diseño y desarrollo de nuevos productos, Tian y College (2010) subrayan el creciente rol que juegan los antropólogos a través de estudios etnográficos en el interior y en el exterior de las compañías, cuyo fin es generar innovación y ventaja competitiva, posicionar marcas, potenciar la eficacia simbólica y comunicativa de la publicidad, pero sobre todo ayudar a vislumbrar 
dónde emergen las oportunidades de negocios que demanden el diseño de nuevos productos o servicios o, en su defecto, la modificación de los ya existentes. Señalan también estos autores el modo creciente en que los diseñadores industriales y de productos de alta tecnología acuden a estrategias de investigación etnográfica como instrumento para acceder a información crucial sobre las opiniones y la percepción que tienen los usuarios de los productos, de los rasgos que los hacen mejores o peores de aquellos que produce la competencia.

El conocimiento que arrojan los ejercicios de campo en términos de la detección de patrones y tendencias que afectan las conductas o creencias de los consumidores, sostienen Tian y College (2010, p.78), se convierte en uno de los insumos más valiosos que orientan la investigación de mercado y la toma de decisiones estratégicas en términos del diseño y lanzamiento de nuevos productos al mercado. Pero esta aproximación al consumo como un fenómeno accesorio a la cadena de producción y transacción de bienes, que es finalmente lo que regula cualquier sistema económico, genera al mismo tiempo un debate en torno a las consecuencias éticas del trabajo etnográfico orientado según las dinámicas del mercado, ello en conjunción con lo que las grandes corporaciones, desde la perspectiva utilitarista, consideran necesario o deseable para la satisfacción de las necesidades humanas y el mejoramiento de la calidad de vida de los clientes, según advierte Sherry (2008).

Graffam (2010) aborda el problema de cómo hacer compatibles la perspectiva que sobre el diseño de nuevos productos y servicios aportan los antropólogos de negocios, con base en estudios sobre el comportamiento cultural, y aquellos modelos abstractos de segmentación del mercado, cuyo fin invariable es inducir a que las personas compren. Para bien o para mal, los antropólogos no siempre tienen éxito en persuadir a la gente de negocios o a los clientes mismos. Jordan (2010) documenta que durante las décadas de los sesenta y setenta, algunas asociaciones de antropólogos en los Estados Unidos manifestaron oposición -argumentando razones éticas- a participar en el desarrollo de proyectos de investigación que no fueran del interés general o en trabajos de consultoría en los que, con el propósito de optimizar el desempeño y elevar los volúmenes de ventas de cualquier género de organización productiva, se pudiera alienar a las personas o manipular los deseos y sentimientos con el fin exclusivo de motivarlos a adquirir determinados bienes o servicios, más aún cuando el beneficio aportado por estos fuera nulo o marginal, o cuando ello implicara la reducción innecesaria o incluso el desperdicio de los recursos de la gente, ya escasos de por sí.

En este punto y en contraste con lo planteado en el párrafo anterior, resulta de suma utilidad citar un fragmento significativo del Buy.ology de Lindstrom (2009, p. 5), 
personaje reconocido en el terreno del neuromarketing, una revolucionaría tendencia en la investigación de mercados que, más allá de considerar el trasfondo cultural que documentan los antropólogos de negocios, explora también los mecanismos subconscientes que determinan las conductas de los consumidores:

\begin{abstract}
No pretendo ayudarles a las empresas a utilizar los estudios del cerebro para controlar la mente de los consumidores o convertirlos en robots. En algún momento, en un futuro no muy lejano, habrá quienes abusen de esa herramienta, pero tengo la esperanza de que la mayoría se valdrá de ella para bien: comprender mejor a los seres humanos mismos -nuestros deseos, nuestras motivaciones y nuestros impulsos- y aprovechar esa clase de conocimiento para fines buenos y prácticos [...] al comprender mejor nuestro comportamiento aparentemente irracional -porqué compramos una camisa de diseñador o cómo evaluamos un candidato para un cargo-, logramos mayor control, no menos. Cuánto más sepamos acerca de porqué caemos ante las estratagemas y las tácticas de los anunciantes, mejor podremos defendernos de ellos. Y cuanto más sepan las empresas acerca de nuestras necesidades y nuestros deseos, más productos útiles y con significado podrán ofrecernos. Después de todo, ¿̇acaso no desean los mercadotécnicos ofrecernos productos que nos enamoren? ¿Cosas que mejoren nuestra vida y con las cuales establezcamos un compromiso emocional? Imagine más productos que generen más dinero y satisfagan a los consumidores al mismo tiempo. La combinación suena muy bien.
\end{abstract}

La posición intelectual de Lindstrom (2009) deja entrever una actitud relativista que, tras ponderar con cierta sobredosis de optimismo los pros y los contras de poner la investigación científica al servicio de las estrategias de mercadeo, termina por hacer apología del consumismo en los mismos términos que lo hacen las corporaciones multinacionales, esto es, como un servicio a la comunidad, casi como un mal necesario, una elección derivada del derecho a vivir la propia emocionalidad e individualidad por medio del libre acceso a productos y servicios por los que se paga. Asimismo, llama la atención una contradicción implícita en la reflexión de Lindstrom (2009, p.5): "cuánto más sepamos acerca de por qué caemos ante las estratagemas y las tácticas de los anunciantes, mejor podremos defendernos de ellos", ¿quién puede defenderse de los anunciantes, los consumidores o los anunciantes mismos? No es difícil suponer que si los consumidores conocieran cada vez mejor cómo funcionan las estrategias de mercadeo, por ejemplo, o los mecanismos simbólicos que explotan los publicistas, ello redundaría en la reducción de los volúmenes de ventas de las compañías, y en tal escenario la labor de los mercadotécnicos sería contraproducente.

En un libro que aborda los alcances teóricos de la sociología del consumo en Norteamérica: El encanto de un mundo desencantado, y donde además se caracteriza la figura simbólica de las catedrales del consumo, Ritzer (2000, p. 67) acude al concepto marxista de medios de consumo, concepto que, si bien es menos conocido que el de medios de producción, es subsidiario de este, como herramienta teórica para explicar cómo el "éxito del capitalismo moderno y las catedrales del consumo dependen, en gran 
medida, del control y de la explotación del consumidor". Dicho control depende, a su vez, de la racionalidad que se construye en torno a las propiedades de los productos que se consumen, si se estiman esenciales para la subsistencia o hacen parte de la esfera de lo lujoso. Pero más más importante aún, escribe Ritzer (2000, p. 71), es que en la economía del libre mercado "el consumo ha ido desplazando en importancia a la producción, lo que ha producido un desplazamiento paralelo del control y explotación de los trabajadores al control y la explotación de los consumidores".

Esta correspondencia entre el control de la producción y el control del consumo, encuentra resonancia en todas aquellas estrategias de mercado en las que la compañía o empresa que vende un determinado producto incorpora, en la forma de otro producto o servicio adicional y a veces bajo la misma marca, medios de consumo como las tarjetas de crédito o los programas de financiamiento, a fin de inducir a los clientes reales y potenciales a consumir más allá de lo que racionalmente permitiría el nivel de ingresos, convirtiéndolos así en deudores cautivos del encanto del consumo. Este control que se da a través de los medios de consumo viene reforzado con fórmulas cada vez más sofisticadas para influenciar el comportamiento de los consumidores, en conjunción con campañas de publicidad que fusionan el producir y el consumir en un valor fundamental al que se subordinan todos los demás actos de la vida.

No constituye ninguna novedad la aplicación del modelo teórico marxista al análisis socio-antropológico de las dinámicas de consumo y en general a la racionalidad de las instituciones de intercambio. Ya Godelier (1978, p. 274) había señalado que la "solidaridad orgánica de las estructuras de un sistema económico se manifiesta por medio de la complementariedad y la circularidad de los procesos, en los que la producción permite el consumo y éste, a su vez, permite la producción", pero este razonamiento que en principio se orienta a la caracterización de sociedades pre-industriales podría carecer de suficiente universalidad, en virtud de que no todas las leyes económicas son aplicables a la totalidad de los sistemas, mucho menos cuando estos han transformado el modo de pensar la realidad del consumo, incorporando nuevas figuras como la globalización de la economía, entendida como proceso objetivo de relaciones sociales, planteado desde una ideología hegemónica: la del capitalismo monopolista.

En este proceso, se incorporan, desde luego, nuevas matrices cognitivas que por medio de la conjunción de estrategias como la publicidad en los medios, el crédito, las marcas, entre muchísimas otras informaciones que invaden la cotidianidad, crean y modelan de manera artificiosa cualidades o atributos en los productos de consumo. Ello implica que el valor de uso de los objetos se sustituya por el valor de cambio, logrando de paso que dichos productos influyan de manera determinante 
en el comportamiento y las actitudes de las personas cautivas en el imaginario de lo global, imaginario que termina por convertirse en una suerte de ideal ético y estético al cual se subordinan los deseos y las voluntades de la colectividad, anulando en último término la posibilidad de cualquier alteridad económica e incluso la existencia del individuo como tal.

\section{CRÍTICA A LA RAZÓN DE LOS NEGOCIOS}

A modo de conclusión transitoria, lo que parece cierto e irreversible frente al panorama actual de antropología de los negocios es que cualquiera sea la orientación de esta en la Contemporaneidad o hacia el futuro (la investigación sobre la cultura organizacional, las consultorías, el marketing), los antropólogos académicos se verán compelidos a renunciar a valores y retóricas, típicos de ciertos enfoques ideológicos que otrora dieron a la disciplina un matiz mucho más humanístico y filosófico. Dicho matiz humanista, documenta Sanjek (2000, p. 99), motivó también que entre las décadas de los cincuenta y los setenta muchos antropólogos en el ámbito académico europeo y norteamericano asumieran una actitud contestataria y se integraran al activismo político y sindical, a la defensa de los derechos civiles de las minorías, a la militancia en movimientos de carácter anticolonialista que denunciaron la pobreza, la desigualdad, la dispersión rural, la explotación del trabajo, la devastación del medio ambiente, entre otros efectos de la economía de mercado.

A contracorriente de lo que se publica en la universidades norteamericanas y europeas con relación a la situación de la antropología aplicada a los negocios internacionales, el papel que juega frente a la actual coyuntura económica mundial, así como las proyecciones hacia el futuro, Hann y Hart (2011) proponen una reflexión crítica frente al excesivo relativismo del que adolecen los antropólogos en el ámbito discursivo de la globalización y bajo el influjo del poder financiero y la economía política promovida de modo unilateral desde las grandes corporaciones, convertidas hoy en autoridades paralelas -o incluso superiores- a la del Estado nación o de la academia. Hann y Hart (2011) analizan de manera muy aguda un conjunto de causas profundas que de manera paulatina propiciaron las condiciones de dominación del mercado sobre la vida de las personas, pero más allá de eso, los mecanismos simbólicos a través de los cuales el mercado determina la forma como las personas se perciben a sí mismas y a los demás. Enfatizan estos autores en la necesidad de evaluar, sobre una base histórica, la realidad de las condiciones materiales que han propiciado un desarrollo económico desigual entre las diferentes regiones del mundo, al tiempo que ven en la actual crisis mundial, una oportunidad para poner a prueba la legitimidad moral de las instituciones económicas globales y los paradigmas de una economía en manos de los economistas. 
La integración efectiva de la disciplina antropológica a la actual dinámica de los negocios, tal y como se entiende en el contexto de lo global, implica una subordinación inexorable a los valores de las corporaciones multinacionales. En correspondencia con la premisa anterior, Tylor y Flint (2002) perciben dicha noción de lo global como todo aquello que para bien o para mal atañe a la generalización del modelo capitalista financiero y la mundialización de una agenda política neoliberal que promueve la privatización y la economía abierta. Pero con respecto a esta concepción, aceptada ahora como si fuera parte del orden natural de las cosas, algunos antropólogos de negocios parecieran soslayar que un balance inocultable del influjo de la globalización sobre la gran masa de sociedades marginales y países pobres del mundo, tal como lo documenta Stiglitz (2003); Stiglitz (2006), no revela otra realidad distinta a la concentración de la riqueza en muy pocas manos.

Por otra parte, la premisa del libre comercio como valor supremo de la globalización, en tanto actividad que integra a diferentes países en una dinámica de intercambios económicos y de continua innovación, excluye el hecho de que lo libre del comercio no se corresponde necesariamente con lo justo del comercio, y ello tiene que ver con la disparidad de condiciones en que los diferentes países participan de dicha dinámica. A este respecto y a propósito de los TLC entre EE. UU. y Latinoamérica Katz (2007, p.16) escribe: "Se resalta, en cambio, la conveniencia del libre comercio con el espejismo de un proyecto optativo [...] Pero basta comparar el PBI de los Estados Unidos con el vigente en cualquier economía de la región, para notar cuán ridícula en la creencia de una negociación entre pares".

Una vez más, emerge el debate ético de si el fin justifica los medios cuando se trata de elevar el desempeño y los volúmenes de venta de una compañía. Pero estas consideraciones evidencian también un rasgo distintivo de la Posmodernidad, que según Rosenau (1992) se manifiesta en la sustitución progresiva de la ciencia y la razón por el conocimiento emocional y las capacidades intuitivas de cada individuo, las posibilidades creativas, la imaginación, la fantasía, la contemplación. También con relación a la incidencia de la corriente posmoderna en el modelo discursivo de la antropología en la Contemporaneidad y en general sobre las ciencias sociales, Harris (1999, p.44) advierte una suerte de "preponderancia del corazón sobre la conciencia, de lo espiritual sobre lo material, $y$ de lo personal sobre lo impersonal".

Sin embargo, resulta útil para este debate reconocer que los métodos y el análisis de la antropología de los negocios no necesariamente tienen que estar orientados hacia la búsqueda del lucro; algunos estudios enfocan la atención en describir cómo diversidad de teorías del valor se ponen en juego cada vez que se verifica una transacción o un negocio entre personas de distintos orígenes nacionales, étnicos, 
grupos de filiación, etc., más allá de la unilateral teoría del valor monetario que gobierna la lógica operativa de los economistas en Occidente. Al respecto, Moeran (2012) sostiene que a través de las técnicas etnográficas y desde una visión culturalista, se logra documentar los conflictos de apreciación que se suscitan cuando la gente evalúa las propiedades, la calidad o lo justo del precio de un determinado artículo, la estrategia visual a través de la cual este se oferta a los consumidores, basándose en parámetros propios de la clase social o nivel de educación, en los ideales estéticos y hasta en los prejuicios morales.

Finalmente, cabe contraponer el carácter ontológico y la estatura moral de una disciplina antropológica que se hace eco de lugares comunes acuñados por el neoliberalismo económico tales como rentabilidad, eficiencia, competitividad, innovación, entre otros, frente a una disciplina antropológica que se hace cargo de las cuestiones generales de la humanidad, en el marco de lo cual aborda el fenómeno de los negocios y la globalización como expresión contemporánea de las instituciones sociales de intercambio, pero con relación a otros fenómenos también globales y no menos importantes como la pobreza, la discriminación, la devastación medioambiental, el subdesarrollo o los conflictos bélicos. Asimismo, se requiere de una antropología que revise la pertinencia de los valores de la Modernidad en el marco de la globalización, que se pregunte por el futuro de las sociedades indígenas y las economías nacionales de escala menor frente a la expansión del capital transnacional, todo ello a riesgo de que esa globalidad que todos aceptan hoy como parte del orden natural de las cosas termine por convertirse en una versión sofisticada de colonialismo en todos los niveles de la vida social. En últimas, una antropología que en lugar de contribuir a hacer homogénea la percepción de lo hegemónico se dé a la tarea de mundializar la diversidad.

\section{BIBLIOGRAFÍA}

Aguilera, Francisco (1996). Is Anthropology Good for the Company? En: American Anthropologist, Vol. $98, \mathrm{~N}^{\circ} 4$, p. $735-742$.

Baba, Marietta (2006). Anthropology and Business. En: Birx, James (ed.). Encyclopedia of Anthropology. Thousand Oaks, CA: Sage Publications, pp. 83-117.

Bourdieu, Pierre (2008). El sentido práctico. Madrid: Siglo XXI de España, 456p.

Chapman, Malcolm (2001). Social Anthropology and Business Studies; some considerations of method. Gellner y Hirsch (eds.), Inside Organizations. Anthropologist at work, Oxford: Berg, p. 19-34.

Eddy, E.M. y Partridge, W.L. (1978). Applied Anthropology in America. N. Y.: Columbia University 
Press, 370p.

Ferraro, Gary (2005). The Cultural Dimension of International Business. N. J.: Pearson Prentice Hall, 214p.

Francesco, Anne Marie y Gold, Barry (2005). International Organizational Behavior. N. J.: Pearson Prentice Hall, 654p.

Godelier, Maurice (1978). Racionalidad e irracionalidad en la Economía. México: Siglo XXI Editores, 313p.

Graffam, Gray (2010). Design Anthropology meets marketing. En: Anthropologica, Vol. 52, N¹, p. $155-164$.

Hann, Chris y Hart, Keith (2011). Economic Anthropology. History, Ethnography, Critique. London: Polity Press, 206p.

Harris, Marvin (1999). Antropología y postmodernismo. En: Cataura. Revista Cubana de Antropología, $N^{\circ}$ 0, p. 44-62.

Jordan, Ann (2010). The Importance of Business Anthropology: Its Unique Contributions. En: International Journal of Business Anthropology, Vol. 1, $\mathrm{N}^{\circ} 1$, p. 15-25.

Katz, Claudio (2007). El rediseño de América Latina. ALCA, MERCOSUR y ALBA. Caracas: El Perro y La Rana, 156p.

Kedia, Satish y Van Willigen, John (2005). Applied Anthropology. Domains of Application. Westport, CT: Greenwood publishing group, 363p.

Lindstrom, Martin (2009). Compradicción. Verdades y mentiras de por qué las personas compran. Bogotá: Norma, 248p.

Malinowski, Bronislaw (1981). Una teoría científica de la cultura. Barcelona: Edhasa, 235p.

Malinowski, Bronislaw (2001). Los argonautas del Pacífico occidental. Comercio y aventura entre los indígenas de la Nueva Guinea melanésica. Barcelona: Península, 685p.

Mauss, Marcel (2009). Ensayo sobre el don. Forma y función del intercambio en las sociedades arcaicas. Madrid: Katz Editores, 269p.

Moeran, Brian (2012). A business anthropological approach to the study of values: evaluate practices in ceramic art. En: Culture and Organization, Vol. 18, N³, p. 195-210.

Ritzer, George (2000). El encanto de un mundo desencantado. Revolución en los medios de consumo. Barcelona: Ariel, 256p.

Roca, Jordi (2001). ¿Antropólogos en la empresa?: a propósito de la (mal) llamada cultura de empresa. En: Etnográfica, Vol. 5, No 1, p. 69-99. 
Rosenau, Pauline Marie (1992). Post-Modernism and the Social Sciences: Insights, Inroads, and Intrusions. N. J.: Princetown University Press, 248p. .

Sanjek, Roger (2000). Política, teoría y la naturaleza de lo cultural. En: Cataura. Revista Cubana de Antropología, $N^{\circ} 1$, p.72-100.

Sherry, John (1988). Teaching International Business: A view from Anthropology. En: Anthropology E Education Quarterly, Vol. 19, N² 4, p. 396 415.

Sherry, John (1995). Contemporary Marketing and Consumer Behavior: An Anthropological Sourcebook. Thousand Oaks, CA: Sage, 482.

Sherry, John (2008). The ethnographer's apprentice: Trying consumer culture from the outside in. En: Journal of Business Ethics, Vol. 80, N 1, p. 85-95.

Stiglitz, Joseph (2003). El malestar de la globalización. Madrid: Taurus, 348p.

Stiglitz, Joseph (2006). La Corporación Multinacional. En: Claves de razón práctica, $N^{\circ}$ 167, p. $16-26$.

Tian, G., Wang, H. y Dai, Q. (2013). Competitive intelligence, knowledge management, and anthropology. En: Modeling and Computation in Engineering II. London: Tylor \& Francis group, p. 305-310.

Tian, Robert y College, Medaille (2010). The Unique Contributions and the Unique Methodologies: A Concise Overview of the Applications of Business Anthropology. En: International Journal of Business Anthropology, Vol. 1, N², p. 70-88.

Tian, R., Lillis, M. y van Marrewijk, Alfons (2010). General Business Anthropology. Miami: North American Business Press, 636p.

Tian, Robert y Walle, Alf (2009). Anthropology and Business Education: practitioner applications for a qualitative method. En: International Journal of Management Education, Vol. 7, № 2, p. $59-67$.

Tylor, Peter y Flint, John (2002). Geografía política. Economía-mundo, Estado-nación y localidad. Madrid: Trama, 447p.

Van Marrewijk, Alfons (2010). European Developments in Business Anthropology. En: International Journal of Business Anthropology, Vol. 1, N1, p. 26-44.

Walle, Alf (2013). Rethinking Business Anthropology: Cultural Strategies in Marketing and Management. Sheffield: Greenleaf Publishing, 221p. 